\title{
The Relationship between Self-Concept and Mental Health among Chinese College Students: The Mediating Effect of Social Adjusting
}

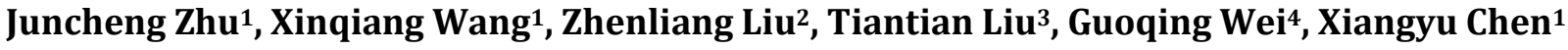 \\ ${ }^{1}$ School of Psychology, Jiangxi Normal University, Nanchang, China \\ ${ }^{2}$ Department of Psychology, School of Social and Behavioral Sciences, Nanjing University, Nanjing, China \\ ${ }^{3}$ School of Education, Shanghai Normal University, Shanghai, China \\ ${ }^{4}$ Chongqing University of Arts and Sciences, Chongqing, China \\ Email:xinqiangw101@163.com
}

How to cite this paper: Zhu, J.C., Wang, X.Q., Liu, Z.L., Liu, T.T., Wei, G.Q. and Chen, X.Y. (2016) The Relationship between Self-Concept and Mental Health among Chinese College Students: The Mediating Effect of Social Adjusting. Open Journal of Social Sciences, 4, 118-125. http://dx.doi.org/10.4236/jss.2016.412011

Received: November 21, 2016

Accepted: December 26, 2016

Published: December 29, 2016

Copyright $\odot 2016$ by authors and Scientific Research Publishing Inc. This work is licensed under the Creative Commons Attribution International License (CC BY 4.0).

http://creativecommons.org/licenses/by/4.0/

\begin{abstract}
Objective: To investigate the mediating effect of social adaptation between the Chinese college's mental health and self-concept. Methods: Five hundred and eight college students were surveyed with China College Student Adjustment Scale (CCSAS), College Student Self-Concept Questionnaire (CSSQ), and Development of Chinese College Student Mental Health Scale (DCCSMH). Using SPSS and the tools of the Bootstrap to explore the mediating effect of social adaptation between the Chinese college's mental health and self-concept. Results: Self-concept, mental health and social adaptation were significant correlated with each other (except for that self-concept, anxious, depending and impulse, social adjusting and forcing). The mediating effects made up $8 \%$ to $20 \%$ of the total effects. Conclusion: Self-concept can directly affect mental health of college students, social adaptation acts as a mediating role between self-concept and mental health among Chinese college students.
\end{abstract}

\section{Keywords}

Self-Concept, Mental Health, Social Adaptation, The Mediating Effect, Chinese College Students

\section{Introduction}

In recent years, with the increasing enrollment of universities throughout the country, the number of college students is increasing year by year. At the same time, with the complexity and diversity of the current society, college students are facing more and more psychological pressure, such as employment, emotional and interpersonal rela- 
tionship. The mental health of college students has increasingly become an issue and hotspot which is noticed and researched by society. Currently, College students in all factors of Symptom Check-List90 (SCL-90) were significantly higher than the norms in 1986 [1] [2]. The number of college students with mental disorder arrived at $20 \%-$ $30 \%$, which is much higher than other social groups [3]. Therefore, the aim of the study was to explore the internal impact factors and the mechanism of action of the psychological health among college students, and to provide an important theoretical and practical significance for the prevention and intervention of college students' psychological health.

Self-concept is the individual's cognition and evaluation of the self and social environment which are formed during the process of socialization, which is the sum of the individual's self-cognition [4] [5]. The formation and development of self-concept is a dynamic and changing process. College day is the period that self-concept goes through fastest development and has the most problems. College Students' understanding and evaluation of self will not only affect their own behavior, but also affect their mental health. It is found that there is a significant positive correlation between self-concept and mental health, which has a strong predictive effect on mental health [6] [7] [8] [9]. Self-concept can prevent the social dysfunction [10], but also can prevent mental health problems [11]. That is to say, college students with good self-concept can make a more objective evaluation of themselves, and actively accept the self, thus regulating and maintaining their own mental health. However, how does self-concept affect the mental health of college students?

Social adaptation refers to the individual in the interaction with the social environment, and constantly learns or modifies the behavior and life-style, and ultimately to maintain a harmonious and balanced state with the social environment [12]. Does social adaptation play an intermediary role in the relationship between self-concept and mental health of college students? At present, there is no relevant literature to explore this issue. It is found that there is a significant positive correlation between self-concept and social adaptation of college students, that is, the lower the self-concept of college students is, the lower the level of their social adaptation is [13]. Relative to the individual with high self-concept, the individual with low self-concept in the fact of social adaptation showed negative features [14]. In addition, social adaptation is one of the crucial factors affecting mental health [15]. For example, researches have found that social adaptation can effectively predict mental health, individuals with poor social adaptation; their mental health status will be also relatively poor [13] [16] [17]. Therefore, it is reasonable to infer that the social adaptation is a mediating variable between selfconcept and mental health of college students.

Overall, self-concept, social adaptation and mental health are closely linked, and social adaptation may act as a link and bridge. Therefore, this study takes college students as the research object, and for three main purposes, one is to explore the relationship among self-concept, social adaptation and mental health; two is to examine the mediating role of social adaptation in self-concept and mental health; three is to reveal the 
internal mechanism that self-concept affects mental health.

This study adopts the method of random cluster sampling, taking the class as a unit. Questionnaire survey was conducted among the undergraduates in a university; subjects filled the questionnaire under unified instructions from staff. Questionnaires were in total 580, and valid questionnaires were 505 . Of the participants, $47.1 \%$ were males $(\mathrm{n}=238) ; 52.9 \%$ were females $(\mathrm{n}=270)$. The ages of the subject range from 17 to 24 $($ Mean $=21.41, \mathrm{SD}=1.35)$.

\section{Materials}

\subsection{China College Student Adjustment Scale}

This study uses the China College Student Adjustment Scales (CCSA), which has been used as china college student adjustment in the former research [16]. The scale has 7 dimensions that interpersonal adjustment, learning adjustment, campus life adjustment, job selection adjustment, emotion adjustment, self adjustment, and life satisfaction, total 60 items. It is a 5-point rating scale (1-2-3-4-5), respectively, from the "completely disagree" to "completely agree". The higher the score, the better the ability of social adaptation. The coefficient of internal consistency of this scale in the present study was 0.883 .

\subsection{College Student Self-Concept Questionnaire}

This study uses the College Student Self-Concept Questionnaire (CSSQ), which has been used as college student self-concept in the former research [18]. The questionnaire has 23 items, $\alpha=0.716$, the retest reliability was 0.785 . The questionnaire has good content validity and constructs validity. It is a 5-point rating scale (1-2-3-4-5), respectively, from the "completely disagree" to "completely agree". The higher the scores, the students' self-concept is more positive, the level of self-development is more higher. The coefficient of internal consistency of this scale in the present study was 0.883 .

\subsection{Development of Chinese College Student Mental Health Scale}

This study uses the Development of Chinese College Student Mental Health Scale (DCCSMH), which has been used as college student mental health in the former research [19]. The scale has 12 dimensions and 96 items, measures of somatization, anxiety, depression, low self-esteem, withdrawal, attack, paranoia, compulsion, dependence, impulsivity, psychological disorders, psychotic tendencies and other mental health problems. The reliability of the subscales is between $0.764-0.893$, which indicates that the scale has good reliability. It is a 5-point rating scale (1-2-3-4-5), respectively, from the "completely disagree" to "completely agree". The higher the score, the more the mental health problems were severe. The coefficient of internal consistency of this scale in the present study was 0.955 .

\subsection{Procedure}

To test the model, data were collected from one university, which adopts the method of 
random cluster sampling. Before the data collection, all participants was signed informed consent.

\section{Data Analyses}

The data were analyzed statistically by SPSS 18.0 and AMOS 22.0. The methods of statistical analysis including descriptive statistics, correlation analysis, Bootstrap test.

\subsection{Statistical Test for Common Method Biases}

According to previous research [20], the study adopts Harman's single way factor analysis to test common method biases; the result shows that when the research data is not rotating, a total of 47 factor, could explain variance of $68.43 \%$. The first factor explains $17.91 \%$ variance, under $40 \%$ of estimate criteria. It is shown that the study has not existed serious common method biases.

\subsection{The Correlation Analysis of College Students' Self-Concept, Social Adaptation and Mental Health}

From the correlation analysis as shown in Table 1, except the self-concept and mental health of three factors (anxiety, dependence and impulse) are no significant correlation. self-concept, social adaptation and mental health are significant positive correlation among various factors.

\subsection{The Test of Mediating Effect}

This research uses Bootstrap test for each mediating effect [21] [22]. First, using repeat random sampling method $(\mathrm{N}=505)$ extracted from the original data of 1000 samples of the Bootstrap, then according to the samples of fitting mediating effect model (Figure 1). Mediating effect index of each path and the mediation effect of $95 \%$ confidence interval (Table 2). If the path coefficient of the $95 \%$ confidence interval does not include zero, indicates that the mediation effect is significant. From the Table 2, the relationship

Table 1. The result of correlation analysis, mean and standard deviation.

\begin{tabular}{|c|c|c|c|c|c|c|c|c|c|c|c|c|c|c|}
\hline & 1 & 2 & 3 & 4 & 5 & 6 & 7 & 8 & 9 & 10 & 11 & 12 & 13 & 14 \\
\hline 13 & $-0.150^{\star *}$ & $-0.168^{\star *}$ & $-0.199^{\star *}$ & $-0.203^{\star *}$ & $-0.203^{\star *}$ & $-0.169^{\star *}$ & $-0.167^{\star \star}$ & -0.079 & $-0.126^{\star *}$ & $-0.143^{\star *}$ & $-0.198^{\star *}$ & $-0.192^{* *}$ & 1 & \\
\hline 14 & $-0.143^{\star *}$ & -0.066 & $-0.152^{\star *}$ & $-0.173^{\star *}$ & $-0.125^{\star *}$ & $-0.223^{\star *}$ & $-0.175^{\star *}$ & $0.116^{\star *}$ & -0.015 & -0.087 & $-0.168^{\star *}$ & $-0.242^{\star *}$ & $0.130^{\star *}$ & 1 \\
\hline$S D$ & 6.024 & 4.904 & 4.945 & 6.554 & 5.596 & 4.597 & 4.782 & 5.627 & 5.995 & 6.865 & 6.021 & 4.662 & 26.142 & 9.781 \\
\hline
\end{tabular}

ps: 1 = somatization, 2 = anxiety, $3=$ depression, $4=$ Inferiority, $5=$ flinch, $6=$ attack, $7=$ bigotry, $8=$ constrain, $9=$ dependency, $10=$ impulsion, $11=$ psychosexual disorder, 12 = psychotic tendencies, $13=$ social adaption, $14=$ self-concept; ${ }^{*} p<0.05,{ }^{* *} p<0.01$.

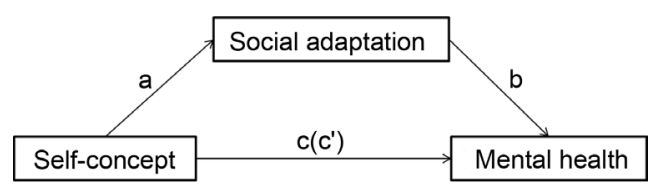

Figure 1. Social adaptation in mediating effect model between self-concept and mental health. 
Table 2. The bootstrap analysis of mediating effect significance test.

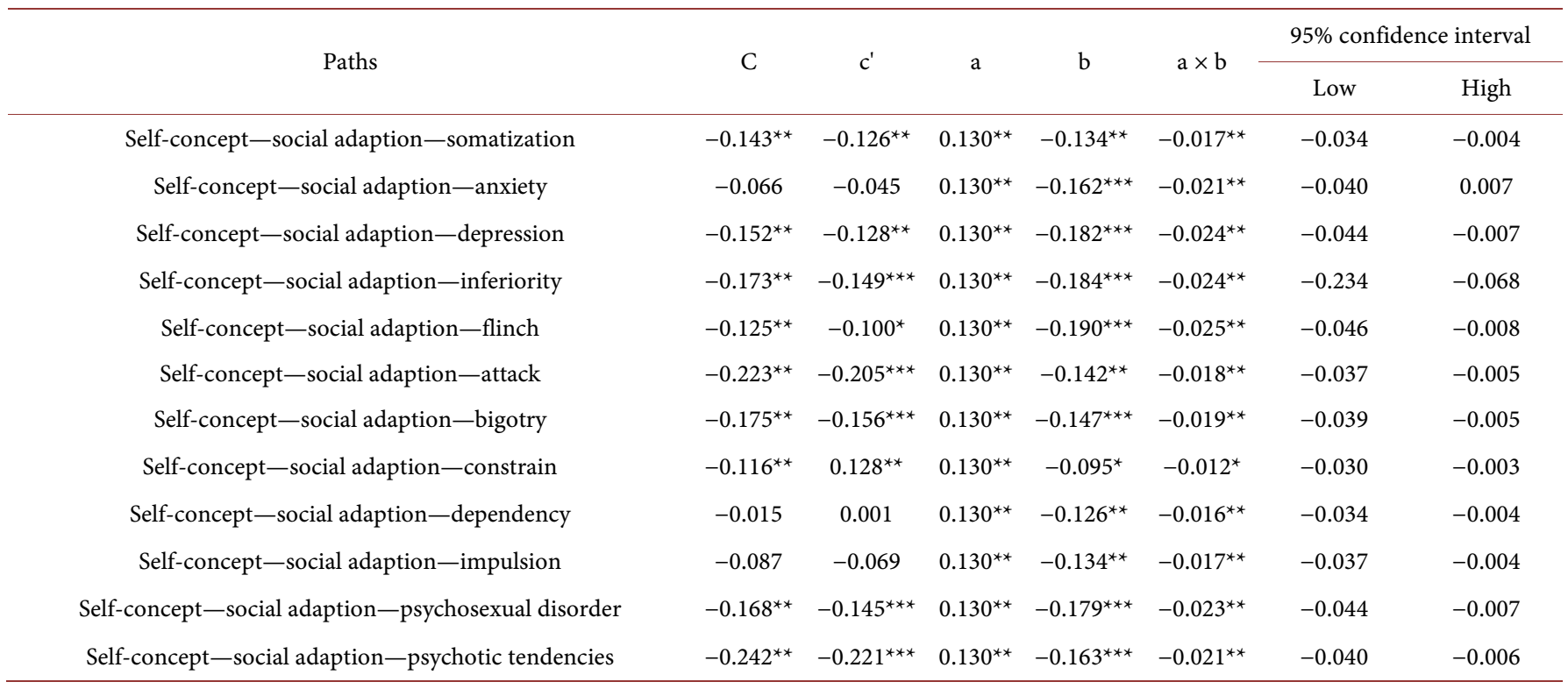

${ }^{*} p<0.05,{ }^{* *} p<0.01$.

between self-concept and mental health of three factors (anxiety, dependence and impulse) are "covered" by social adaptation, which belongs to cover effect [20] [23]. Others factors, the $95 \%$ confidence interval of the path does not contain zero, which social adaptation is verified in the partial mediation effect of self-concept and mental health. The proportion of mediation effect respectively that somatization $=12 \%$, depression $=$ $16 \%$, Inferiority $=14 \%$, flinch $=20 \%$, attack $=8 \%$, bigotry $=11 \%$, constrain $=10 \%$, dependency $=16 \%$, psychosexual disorder $=14 \%$, psychotic tendencies $=9 \%$.

\section{Discussion}

From the correlation analysis, we can see that there is a significant positive correlation between the factors of self-concept, social adaptation and mental health, in addition to self-concept and anxiety, dependence and impulse. The result is consistent with the conclusions of previous studies [4] [7] [9] [24], this shows there is a close relationship among self-concept, social adaptation and mental health. It can be seen from the test results of mediating effect that self-concept can not only influence the mental health directly, but also affect the mental health indirectly through the social adaptation. But the relationship between self-concept and the three factors (anxiety, dependence, impulse) are "covered" by social adaptation. This is consistent with the results of the correlation analysis, which shows the influence of self-concept on the mental health of three health factors (anxiety, dependence and impulse) are restricted by social adaptation.

In this study, social adaptation plays a mediating role between self-concept and mental health of college students. This shows that self-concept can not only affect mental health directly, but also affect the mental health indirectly through social adap- 
tation. The time of university is the period of development, change and maturity of self-concept. Besides, having a good self-concept and a positive self-acceptance will help students to actively regulate and maintain their own mental health. On the contrary, the negative self-concept will cause a lot of bad social behavior, such as aggression, infraction, crime and psychological problem (depression and neurosis, etc.). [25] [26]. Self-concept, of course, is not an independent factor that affects mental health. It also needs to through the interaction between social adaptation and environment, and then influence the mental health. Self-concept through a good social adaptation can provide the power and source for mental health, and poor social adaptation will lead to the hidden trouble about the more psychological problems.

\section{Conclusions}

In short, self-concept as an internal factor, social adaptation as an external factor, the two play crucial role in mental health. Among them, self-concept not only has a directly impact on mental health, but also indirectly impacts on mental health through the social adaptation, namely, the mediating effect, such as inferiority, aggression and paranoia, etc. In addition, social adaptation, in turn, suppresses self-concept, namely, the cover effect, such as anxiety, dependence, and impulse. Therefore, the conclusion of this study has two implications for the prevention and intervention of college students' mental health: First, self-concept and social adaptation should be meanwhile considered, especially in the college students' mental health prevention and intervention. Second, enhance and even strengthen the social adaptation of college students, functions of social adaptation as bridge should be fully exerted.

Naturally, there are still limitations in this study that can be improved in future research. First, this study adopts the cross-sectional study design which could not get the conclusion of causality. Second, this study adopts self-report measurement way, so the social desirability may influence the result. Third, longitudinal studies or experiments could be considered in future research.

\section{Acknowledgements}

This work was supported by the Science foundation for Young Scholars of Jiangxi Province (20151BAB215033); the postdoctoral Science Foundation of Jiangxi Province (2014KY52, 2014RC11); the graduate student innovation project of Jiangxi Province (YC2016-S136); and the MOE (Ministry of Education in China) Project of Humanities and Social Sciences (16YJCZH105).

\section{References}

[1] Jiao, L.Y., Zhang, H.W. and Chen, J. W. (2007) Analysis of Mental Health Status and Personality of Medical College Students. China Journal of Health Psychology, 15, 231-234.

[2] Li, W.J (2009) Survey of Mental Health of College Students and Countermeasures. Health Medicine Research \& Practice, 6, 9-11.

[3] Zhou, A.P. (2010) Investigation and Analysis of Psychological Health in Gansu Province 
college students. Journal of Suzhou Education Institute, 13, 15-17.

[4] Fan, F.M. and Fu, J.Y. (2001) Self-Concept and Mental Health of College Students. Chinese Mental Health Journal, 15, 76-77.

[5] Byrne, B.M. (1986) Self-Concept/Academic Achievement Relations: An Investigation of Dimensionality, Stability, and Causality. Canadian Journal of Behavioural Science, 18, 173-186. https://doi.org/10.1037/h0079982

[6] Li, C.N., Zhang, M. and Feng, J.X. (2010) Family Functioning and Social Adjustment: The Mediating Effect of Autonomy. Psychological Development \& Education, 26, 371-377.

[7] Li, J. (2005) Research on Relationship between Self-Concept and Mental Health of Medical College Students. Modern Preventive Medicine, 32, 908-909.

[8] Nie, Y.G., Lin, C.D., Peng, Y.S., Ding, L. and Gan, X.Y. (2008) The Development Characteristic of Adolescents' Social Adaptive Behavior. Acta Psychologica Sinica, 40, 1013-1020. https://doi.org/10.3724/SP.J.1041.2008.01013

[9] Xi, H.L. and Wang, G.F. (2005) Research of Relationship between Self-Concept of Adolescence and Psychological Health. Theory and Practice of Education, 22, 731-745.

[10] Ybrandt, H. (2008) The Relation between Self-Concept and Social Functioning in Adolescence. Journal of Adolescence, 31, 1-16.

[11] Gilman, R. and Huebner, E.S. (2006) Characteristics of Adolescents Who Report Very High Life Satisfaction. Journal of Youth \& Adolescence, 35, 293-301. https://doi.org/10.1007/s10964-006-9036-7

[12] Chen, J.W. and Wang, T. (2004) Social Adaptation and Mental Health. Journal of Southwest China Normal University, 30, 34-39.

[13] Zhang, S., Sun, H. and Zeng, Y.L. (2015) The Study of the Relationship between the College Students' Self-Concept and Social Adaptation. Journal of Tonghua Normal Uninversity, 3, 137-140.

[14] Chen, F.X. and Zhang, F.J. (2010) The Characteristics and Relationships of Peer Attachment, Self-Concept and Loneliness of Students in Reform School. Psychological Development \& Education, 26, 73-80.

[15] Jiang, Q.Y., Xu, N.F. and Cao, J.P. (2010) Effect of Coping Style and Social Adjustment on Mental Health of Undergraduates. Chinese Journal of Health Statistics, 27, 25-27.

[16] Fang, X.Y., Wo, J.Z. and Lin, X.Y. (2005) Development of Chinese College Student Adjustment Scale. Studies of Psychology \& Behavior, 3, 95-101.

[17] Li, Y.M. and Li, Y.X. (2015) Adolescents' Interpersonal Competence, Social Inferiority and Mental Health: The Mediating Role of Social Adaptiveness. Journal of Psychological Science, 38, 109-115.

[18] Liu, T.Y. (2009) Research on the Relationship between College Students' Self-Concept, Interpersonal Relationship and Subjective Well-Being. Master Thesis, Liaoning Normal University, Dalian.

[19] Zheng, R.C., Deng, L.F., Zhang, Z.H. and Guo, Z.L. (2005) Development of Chinese College Student Mental Health Scale. Studies of Psychology \& Behavior, 3, 102-108.

[20] Richardson, H.A., Simmering, M.J. and Sturman, M.C. (2009) A Tale of Three Perspectives: Examining Post Hoc Statistical Techniques for Detection and Correction of Common Method Variance. Organizational Research Methods, 12, 762-800. https://doi.org/10.1177/1094428109332834

[21] Shrout, P.E. and Bolger, N. (2002) Mediation in Experimental and Nonexperimental Studies: New Procedures and Recommendations. Psychological Methods, 7, 422-445. 
https://doi.org/10.1037/1082-989X.7.4.422

[22] Wen, Z., Marsh, H.W. and Hau, K.-T. (2010) Structural Equation Models of Latent Interactions: An Appropriate Standardized Solution and Its Scale-Free Properties. Structural Equation Modeling: A Multidisciplinary Journal, 17, 1-22.

https://doi.org/10.1080/10705510903438872

[23] Wen, Z.L. and Ye, B.J. (2014) Analyses of Mediating Effects: The Development of Methods and Models. Advances in Psychological Science, 22, 731-745.

[24] Zhang, Z.Y. and Zhang, H.D. (2009) Research on the Relationship between Self-Concept and Mental Health of University Students. Journal of Guangzhou Open University, 9, 17-22.

[25] Marsh, H.W., Parada, R.H. and Ayotte, V. (2004) A Multidimensional Perspective of Relations between Self-Concept (Self Description Questionnaire II) and Adolescent Mental Health (Youth Self-Report). Psychological Assessment, 16, 27-41.

https://doi.org/10.1037/1040-3590.16.1.27

[26] Kuzucu, Y., Bontempo, D.E., Hofer, S.M., Stallings, M.C. and Piccinin, A.M. (2014) Developmental Change and Time-Specific Variation in Global and Specific Aspects of SelfConcept in Adolescence and Association with Depressive Symptoms. Journal of Early Adolescence, 34, 638-666. https://doi.org/10.1177/0272431613507498

Submit or recommend next manuscript to SCIRP and we will provide best service for you:

Accepting pre-submission inquiries through Email, Facebook, LinkedIn, Twitter, etc.

A wide selection of journals (inclusive of 9 subjects, more than 200 journals)

Providing 24-hour high-quality service

User-friendly online submission system

Fair and swift peer-review system

Efficient typesetting and proofreading procedure

Display of the result of downloads and visits, as well as the number of cited articles

Maximum dissemination of your research work

Submit your manuscript at: http://papersubmission.scirp.org/

Or contact jss@scirp.org 